\title{
Influence of Austenitizing Temperature on the Microstructure and Corrosion Resistance of 55Cr18Mo1VN High-Nitrogen Plastic Mould Steel
}

\author{
Hua-Bing $\mathrm{Li}^{1,2} \cdot$ Wei-Chao Jiao ${ }^{1} \cdot \mathrm{Hao}^{\mathrm{Feng}}{ }^{1} \cdot$ Zhou-Hua Jiang $^{1} \cdot$ Cui-Dong Ren ${ }^{1}$
}

Received: 15 August 2016/Revised: 8 October 2016/Published online: 31 October 2016

(C) The Chinese Society for Metals and Springer-Verlag Berlin Heidelberg 2016

\begin{abstract}
The influence of austenitizing temperature on the microstructure and corrosion resistance of 55Cr18Mo1VN high-nitrogen plastic mould steel was investigated. The microstructure, elemental distribution and Cr-depleted zone of different heat-treated samples were investigated by X-ray diffraction, electron probe microanalyzer analysis, and transmission electron microscopy. The corrosion resistance was evaluated using electrochemical measurements, and the analysis of passive film was carried out by X-ray photoelectron spectroscopy. The results indicated that the volume fraction of precipitates decreased, and the homogeneity of elements was improved with increasing austenitizing temperature. The degree of Cr-depleted zone around coarse $M_{23} \mathrm{C}_{6}$ was severer than that around $M_{2} \mathrm{~N}$, and pitting corrosion initiated preferentially around $M_{23} \mathrm{C}_{6}$. The corrosion resistance of the samples increased with the austenitizing temperature. With the increase in austenitizing temperature, the passive film was thickened and $\mathrm{Cr}(\mathrm{III})_{\mathrm{Cr}_{2} \mathrm{O}_{3}}$ in the inner layer of passive film was enriched, which enhanced the corrosion resistance of the steel. The higher content of nitrogen in solid solution at higher austenitizing temperature contributed to the increased intensity of $\mathrm{CrN}$ and $\mathrm{NH}_{3}$, leading to the increase in $\mathrm{pH}$ value in the pit, and promoting the repassivation of $55 \mathrm{Cr} 18 \mathrm{Mo} 1 \mathrm{VN}$ steel.
\end{abstract}

\section{KEY WORDS: High-nitrogen plastic mould steel; Austenitizing temperature; Microstructure; Corrosion resistance; Cr-depleted zone}

\section{Introduction}

The continuous and rapid development of plastic industry has increased the demands for plastic mould steel with high hardness and wear resistance, good polishability and

Available online at http://link.springer.com/journal/40195

Hua-Bing Li

huabing_li@163.com

$\triangle$ Hao Feng

fenghao241@163.com

1 School of Metallurgy, Northeastern University, Shenyang 110819, China

2 Key Laboratory for Ecological Metallurgy of Multimetallic Mineral (Ministry of Education), Northeastern University, Shenyang 110819, China outstanding corrosion resistance [1]. Corrosive medium, such as $\mathrm{HCl}, \mathrm{HF}$ and $\mathrm{SO}_{2}$, was released during the manufacturing of plastic products [2], which were aggressive to plastic moulds and accelerated their failure. As an important alloying element, nitrogen is normally added into mould steel to improve its corrosion resistance and hardness [3]. In addition, nitrogen in steel contributes to inhibiting the formation of $\delta$-ferrite and chromium-rich coarse eutectic carbides, avoiding the negative impacts on polish ability, fatigue capabilities and corrosion resistance [4]. However, the content of nitrogen in martensitic stainless steel is limited because of the low-nitrogen solubility under atmospheric pressure. Pressurized metallurgy is an effective method for the production of high-nitrogen martensitic stainless steel, such as $30 \mathrm{Cr} 15 \mathrm{Mo} 1 \mathrm{~N}, 30 \mathrm{Cr} 13 \mathrm{~N}$ and $55 \mathrm{Cr} 18 \mathrm{Mo} 1 \mathrm{VN}$ with uniform composition and 
compact structure [3]. The 55Cr18Mo1VN high-nitrogen plastic mould steel with about $0.25 \mathrm{wt} \% \mathrm{~N}$ has been developed recently using pressured induction melting in Northeastern University, China. With higher hardness and better corrosion resistance, the $55 \mathrm{Cr} 18 \mathrm{Mo} 1 \mathrm{VN}$ steel could meet more rigorous requirements for plastic mould steel.

For plastic mould steel, austenitization is a transition but indispensable process for the heat treatment, which decides the effective grain size, distribution of insolvable precipitates and retained austenite, and exerts an important influence on the strength and corrosion resistance [5]. Choi et al. [6] and Lu et al. [7] investigated the effect of austenitizing temperature on the corrosion performance of the $3 \mathrm{Cr} 13$ plastic mould steel in chloride aqueous solution and found that the corrosion resistance increased with increasing austenitizing temperature. As reported, pitting corrosion always initiates in Cr-depleted zone adjacent to precipitates, which is closely related to austenitizing temperature [8]. So the undissolved precipitates after quenching would affect the corrosion resistance of the plastic mould steel. Additionally, improper austenitization treatment may induce decarburization, grain coarsening and formation of $\delta$-ferrite [9]. Therefore, austenitizing temperature is very important to obtain high-quality plastic mould steel. However, little literature can be found about the heat treatment and corrosion properties of newly developed 55Cr18Mo1VN high-nitrogen plastic mould steel.

The aim of the present research is to reveal the effect of austenitizing temperature on the microstructure and corrosion resistance of $55 \mathrm{Cr} 18 \mathrm{Mo} 1 \mathrm{VN}$ high-nitrogen plastic mould steel. The phase constitution, precipitates, elemental distribution and passive film in samples austenitized at different temperatures were investigated by X-ray diffraction (XRD), electron probe microanalyzer (EPMA), transmission electron microscopy (TEM) and X-ray photoelectron spectroscopy (XPS). The corrosion resistance of the high-nitrogen plastic mould steel was investigated using open-circuit potential (OCP), potentiodynamic polarization and electrochemical impedance spectrum (EIS). Meanwhile, the pitting corrosion mechanisms of the samples austenitized at different temperatures were discussed.

\section{Experimental Procedures}

\subsection{Material and Heat Treatment}

The investigated $55 \mathrm{Cr} 18 \mathrm{Mo} 1 \mathrm{VN}$ high-nitrogen plastic mould steel was melted using a $25-\mathrm{kg}$ pressurized induction furnace, and its chemical composition is shown in Table 1 . The ingot was forged into $35-\mathrm{mm}$ square slab in the temperature range of $1100-1150{ }^{\circ} \mathrm{C}$. Then, the slab was kept at $1200{ }^{\circ} \mathrm{C}$ for $2 \mathrm{~h}$ and hot rolled into 7 -mm-thick
Table 1 Chemical composition of 55Cr18Mo1VN high-nitrogen plastic mould steel (wt \%)

\begin{tabular}{lllllllll}
\hline $\mathrm{C}$ & $\mathrm{Si}$ & $\mathrm{Mn}$ & $\mathrm{Cr}$ & $\mathrm{Mo}$ & $\mathrm{N}$ & $\mathrm{V}$ & $\mathrm{P}$ & $\mathrm{S}$ \\
\hline 0.54 & 0.45 & 0.40 & 17.30 & 0.98 & 0.26 & 0.10 & 0.023 & 0.0021 \\
\hline
\end{tabular}

plates for the subsequent testing. The plates were annealed, then fully austenitized at different temperatures $(940,980$, 1020, 1060 and $1100{ }^{\circ} \mathrm{C}$ ) for $0.5 \mathrm{~h}$, followed by oil quenching. The heat treatment process curve is shown in Fig. 1.

\subsection{Microstructure and Localized Chemical Analysis}

XRD analysis of the annealed and austenitized specimens was performed on a Rigaku/SMART Lab X-ray diffractometer with $\mathrm{Cu} K_{\alpha}$ radiation. To observe the microstructure and distribution of elements $(\mathrm{C}, \mathrm{N}$ and $\mathrm{Cr})$, the specimens were etched for $5 \mathrm{~s}$ in the etchant consisting of $1 \mathrm{~g} \mathrm{~K}_{2} \mathrm{SO}_{3}, 15 \mathrm{~mL} \mathrm{HCl}$ and $50 \mathrm{~mL}$ distilled water, and then examined by EPMA (JXA-8530F). TEM (JEM2100F) observation was carried out to identify the precipitates and analyse the micro chemical composition of the precipitates. The samples for TEM analysis were grinded to $0.05 \mathrm{~mm}$ in thickness with a diameter of $3 \mathrm{~mm}$, and then twin-jet electro-polished in electrolyte consisting of $8 \%$ perchloric acid, $10 \%$ ethylene glycol monobutyl ether and $82 \%$ alcohol solution at $-20{ }^{\circ} \mathrm{C}$. The composition of the passive film was characterized by XPS (ESCALAB 250) with a monochromatic $\mathrm{Al} K_{\alpha}(1486.6 \mathrm{eV})$. The $\mathrm{C} 1 s$ peak at $284.6 \mathrm{eV}$ was used as a reference to correct the binding energies. The peak identification was performed using XPS peak 4.1 by referencing to a database of XPS.

\subsection{Electrochemical Measurements}

The samples used for electrochemical measurements were cut from the plates under different heat-treated conditions and then mounted in cured epoxy resin, leaving an exposed area of $1 \mathrm{~cm}^{2}$. Prior to electrochemical tests, the specimens were wet grounded to 2000 grit $\mathrm{SiC}$ paper. All the electrochemical measurements were performed in aerated $3.5 \mathrm{wt} \% \mathrm{NaCl}$ aqueous solution at $30^{\circ} \mathrm{C}$. And the tests were carried out using a Gamry Reference 600 potentiostat, comprising a thin platinum plate as the counter electrode (CE), a saturated calomel electrode (SCE) as the reference electrode and the sample as the working electrode (WE). In order to remove the original oxide film on the surface of the working electrode, cathodic polarization at $-1 \mathrm{~V} / \mathrm{SCE}$ was performed for $300 \mathrm{~s}$. Then, the OCP was conducted for $1200 \mathrm{~s}$ to approach stable condition. The potentiodynamic 


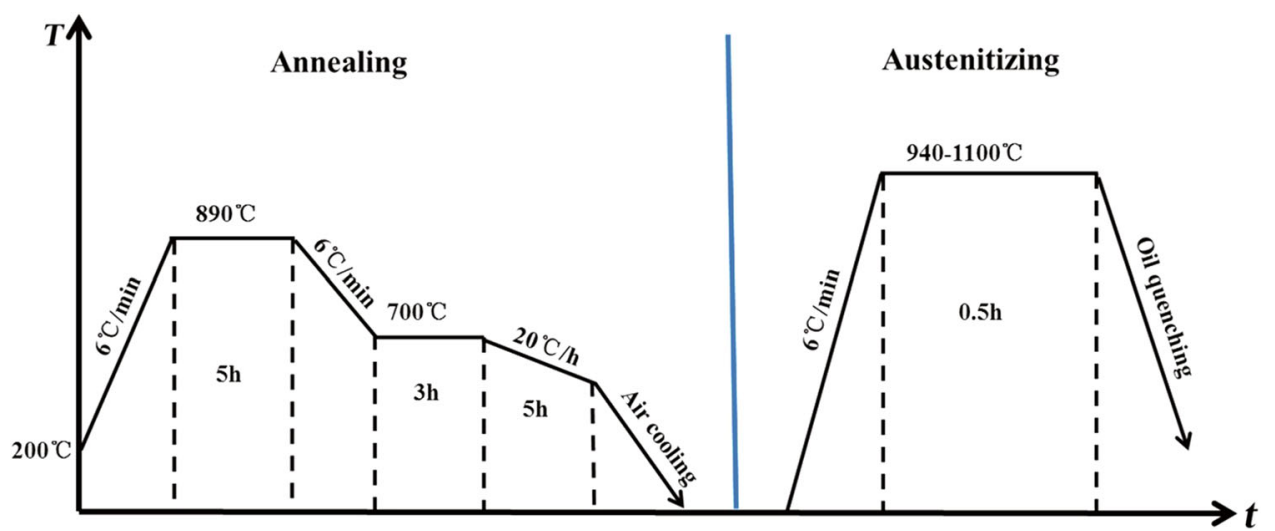

Fig. 1 Heat treatment process curves of the specimens

polarization was swept at a rate of $0.333 \mathrm{mV} / \mathrm{s}$ from $-0.3 \mathrm{~V} / \mathrm{OCP}$ to the anodic direction and finished when the current density exceeded $0.1 \mathrm{~mA} / \mathrm{cm}^{2}$. The EIS experiments were performed with $10 \mathrm{mV}$ amplitude perturbation in the frequency ranging from $100 \mathrm{kHz}$ to $10 \mathrm{mHz}$. The experimental results were analysed using the equivalent circuit embedded in Gamry Instruments Echem Analyst software.

\subsection{Surface Observation of Pit Initiation Sites}

To observe the pit initiation sites, the electrochemical samples were polished using $2.5 \mu \mathrm{m}$ diamond paste. Potentiodynamic polarization was carried out to induce the pitting corrosion. When the potential arrived at $50 \mathrm{mV}$ below the pitting potential $\left(E_{\text {pit }}\right)$, the experiments ended. The pit initiation sites were observed by field emission scanning electron microscopy (FE-SEM, Carl Zeiss Ultra Plus) equipped with energy-dispersive spectroscopy (EDS).

\section{Results}

\subsection{Microstructure Evolution of 55Cr18Mo1VN}

Figure 2a exhibits the XRD results of the samples under annealed and austenitized condition. The diffraction peaks of $\alpha$ phase with body-centred cubic (bcc) structure can be obviously observed in all of the samples. But, it is difficult to distinguish between martensite and ferrite by XRD analysis because of the same axial ratio. The hardness of the annealed sample was 17.2 HRC, while those of the austenitized samples were higher than $36.0 \mathrm{HRC}$. Based on the hardness results, $\alpha$ phases in annealed and austenitized samples were ferrite and martensite, respectively. The $\gamma$ phase can be clearly found in the samples austenitized at 1020 and $1100{ }^{\circ} \mathrm{C}$, which was regarded as retained austenite. The intensity of $\gamma$ diffraction peaks increased and $\alpha$ peaks decreased with increasing austenitizing temperature. The high $\mathrm{C}$ and $\mathrm{N}$ content in matrix due to dissolution of precipitates at high austenitizing temperatures (1020 and $1100{ }^{\circ} \mathrm{C}$ ) enhanced the stability of austenite [7]. Additionally, the peaks for $M_{2} \mathrm{~N}$ were detected in samples annealed and austenitized at 940 and $1020{ }^{\circ} \mathrm{C}$.

The detailed information of the weak peaks in Fig. $2 \mathrm{a}$ within the $2 \theta$ range of $47-54^{\circ}$ is shown in Fig. $2 \mathrm{~b}$. The diffraction angles matched by the software were $48.44^{\circ}$, $50.84^{\circ}$ and $51.60^{\circ}$ for samples annealed and austenitized at $940{ }^{\circ} \mathrm{C}$, which were considered as the diffraction peaks of $M_{23} \mathrm{C}_{6}$, corresponding to the plane of (440), (531) and (442). The content of Cr-rich $M_{23} \mathrm{C}_{6}$ and $M_{2} \mathrm{~N}$ decreased with the increase in austenitizing temperature. And $M_{23} \mathrm{C}_{6}$ and $M_{2} \mathrm{~N}$ totally dissolved into the matrix above $1020{ }^{\circ} \mathrm{C}$, or the content was below the detection level of XRD.

The microstructure evolution of the heat-treated samples observed via EPMA is shown in Fig. 3. Combined with the analysis of XRD, the microstructure of annealed sample consisted of ferrite and mixture of spheroidized $\mathrm{Cr}$-rich $M_{23} \mathrm{C}_{6}$ and $M_{2} \mathrm{~N}$ (Fig. 3a). It could be evidently seen that the size and density of precipitates in annealed sample was much larger than those of the austenitized samples. With the increase in austenitizing temperature, the amount of precipitates deceased obviously (Fig. 3b-d). And coarse lath martensite with few precipitates could be observed in the sample austenitized at $1100{ }^{\circ} \mathrm{C}$ (Fig. 3d). The microstructure of $55 \mathrm{Cr} 18 \mathrm{Mo} 1 \mathrm{VN}$ was partially or entirely transformed into martensite after quenching, and the typical lath martensite was easily observed at relatively high austenitizing temperature. Besides, the morphologies showed that with increasing austenitizing temperature, the volume fraction of retained austenite also increased.

\subsection{Characterization of Precipitates}

The elemental distribution maps for $\mathrm{C}, \mathrm{N}$ and $\mathrm{Cr}$ via EPMA in samples austenitized at 940, 1020 and $1100{ }^{\circ} \mathrm{C}$ are 

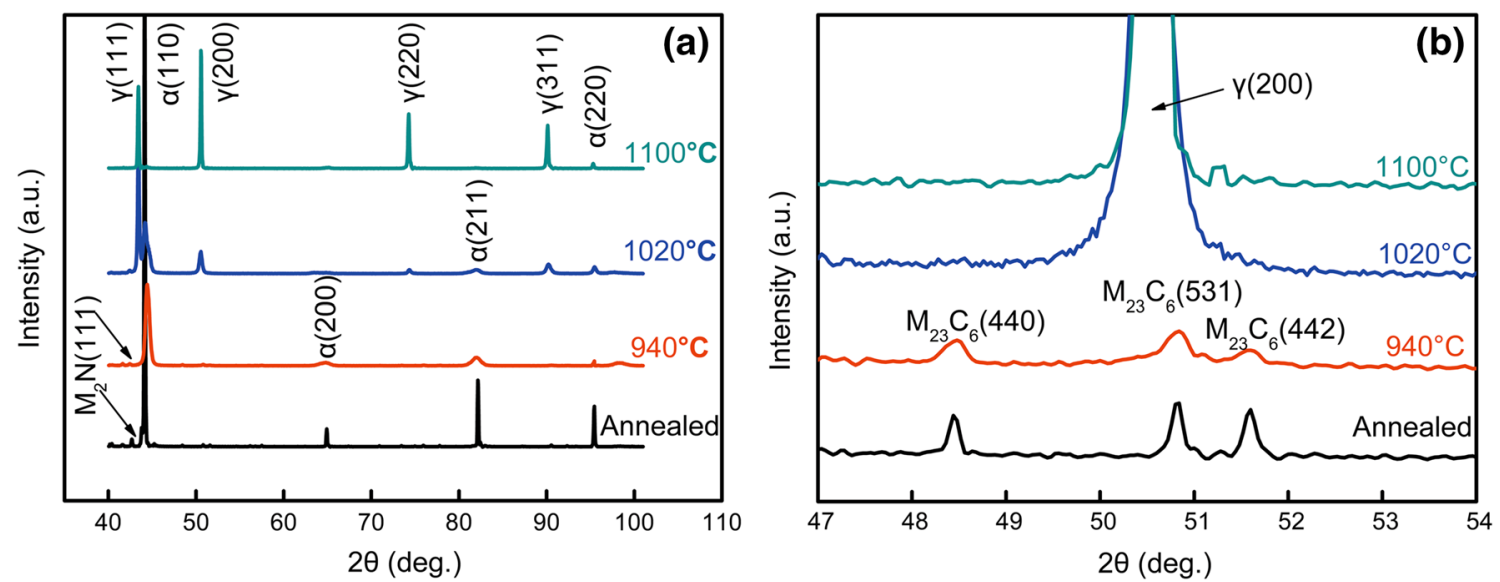

Fig. 2 XRD patterns of the $55 \mathrm{Cr} 18 \mathrm{Mo} 1 \mathrm{VN}$ samples after different heat treatments: a diffraction angles from $40^{\circ}$ to $100^{\circ}$; b detail information between $47^{\circ}$ and $54^{\circ}$
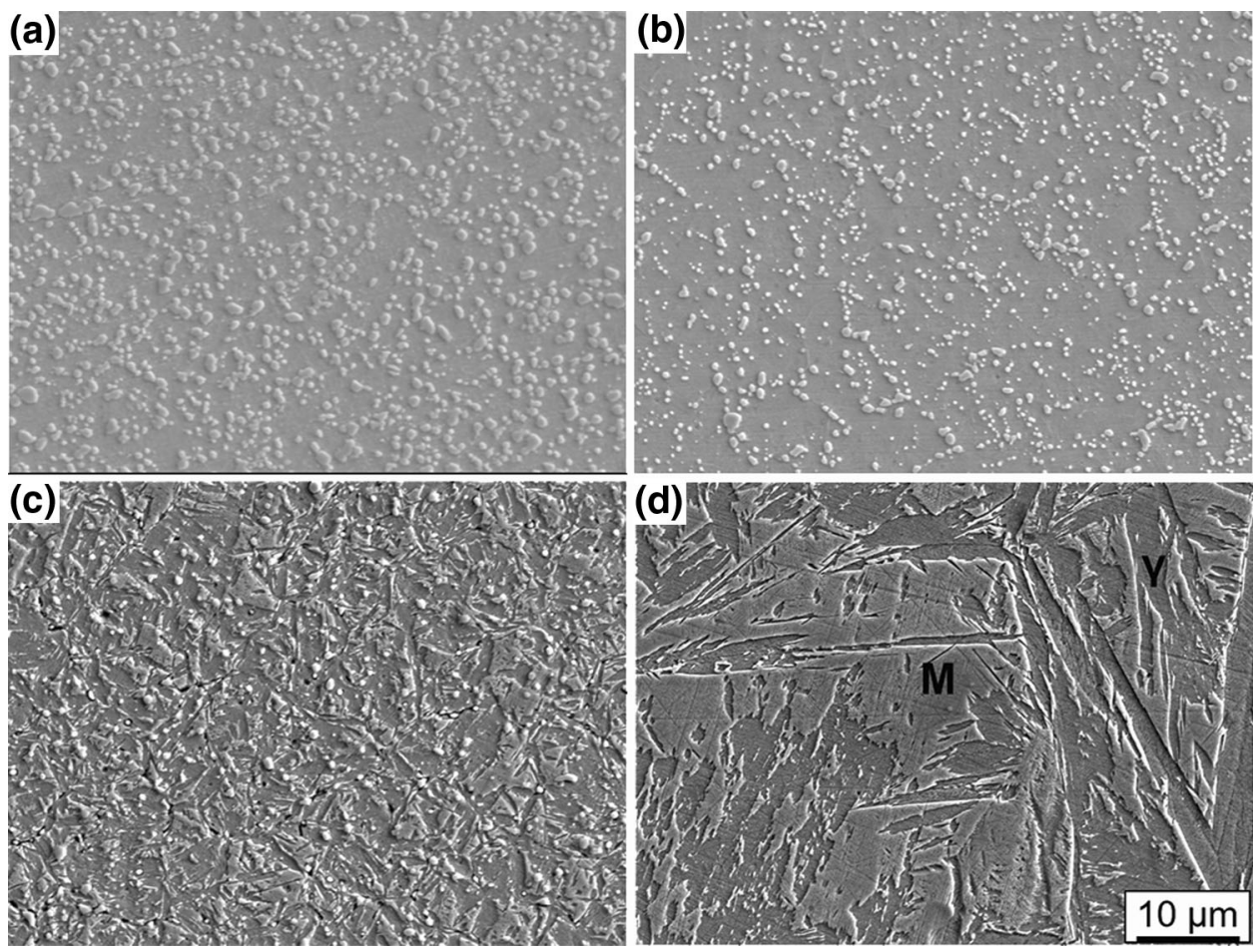

Fig. 3 Microstructure of the heat-treated $55 \mathrm{Cr} 18 \mathrm{Mo} 1 \mathrm{VN}$ : a annealed and austenitized at b $940{ }^{\circ} \mathrm{C}$; c $1020{ }^{\circ} \mathrm{C}$; d $1100{ }^{\circ} \mathrm{C}$

exhibited in Fig. 4. It can be seen that the $\mathrm{C}, \mathrm{N}$ and $\mathrm{Cr}$ were enriched in precipitates (Fig. 4a, b). The volume fraction of carbides was much higher than that of nitrides, due to higher atomic friction of nitrogen in nitrides compared with carbon in carbides [10]. The volume fraction of carbides and nitrides decreased with increasing austenitizing temperature, and the elemental distribution became more uniformly. The content of $\mathrm{C}, \mathrm{N}$ and $\mathrm{Cr}$ in matrix increased with the increase in austenitizing temperature. Analysis of $\mathrm{C}$ distribution via EPMA confirmed that carbon in samples austenitized at 940 and $1020{ }^{\circ} \mathrm{C}$ and sample austenitized at
$1100{ }^{\circ} \mathrm{C}$ mainly concentrated in carbides and matrix, respectively.

To clearly identify the precipitates in $55 \mathrm{Cr} 18 \mathrm{Mo} 1 \mathrm{VN}$, TEM were used to characterize the type of carbides and nitrides in the sample austenitized at $940{ }^{\circ} \mathrm{C}$ (Fig. 5). Plate precipitates of $\mathrm{Cr}_{23} \mathrm{C}_{6}$ with cubic structure and $\mathrm{Cr}_{2} \mathrm{~N}$ with hexagonal structure were observed. The $\mathrm{Cr}_{23} \mathrm{C}_{6}$ and $\mathrm{Cr}_{2} \mathrm{~N}$ were also obtained by XRD in the sample austenitized at $940{ }^{\circ} \mathrm{C}$ (Fig. 2). Similar residual precipitates were observed by Toro et al. [11] and Sun et al. [12]. In addition, the precipitation of $\mathrm{Cr}_{2} \mathrm{~N}$ was coherent with the alloy 

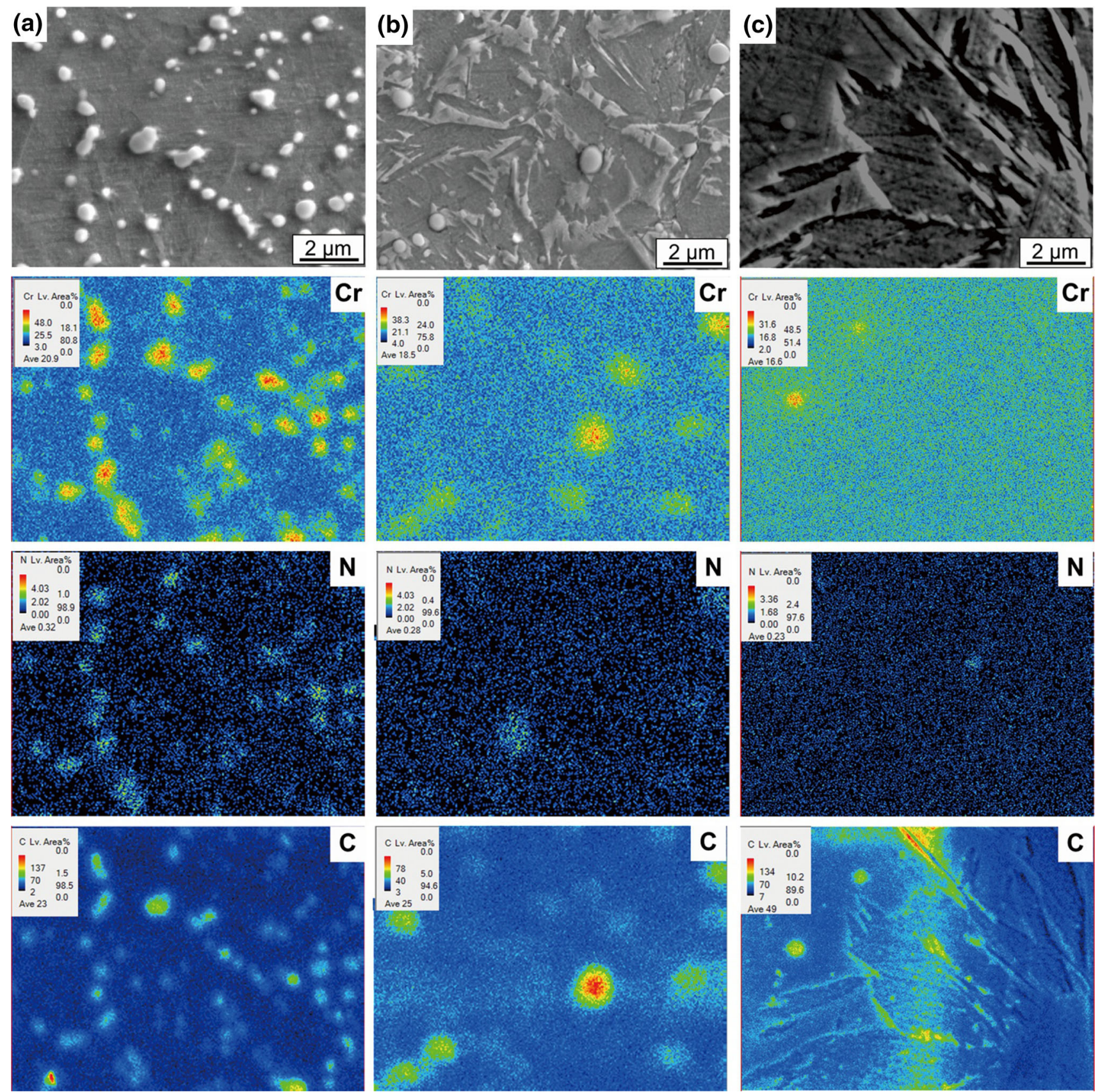

Fig. 4 Elemental distribution maps (Cr, N and C) via EPMA of samples austenitized at: a $940{ }^{\circ} \mathrm{C}$; b $1020{ }^{\circ} \mathrm{C} ; \mathbf{c} 1100{ }^{\circ} \mathrm{C}$

matrix, delaying the growth of $\mathrm{Cr}_{2} \mathrm{~N}$, so, the size of $\mathrm{Cr}_{2} \mathrm{~N}$ is smaller than that of $\mathrm{Cr}_{23} \mathrm{C}_{6}$ [13].

\subsection{Corrosion Behaviour of 55Cr18Mo1VN}

Figure 6 shows the evolution of OCP for the samples under annealed and austenitized conditions in $3.5 \mathrm{wt} \% \mathrm{NaCl}$ aqueous solution for $1200 \mathrm{~s}$. According to the curves, it can be seen that all the curves exhibited an enormous increase in the first $400 \mathrm{~s}$, and then the potential reached a comparatively state. No serious fluctuation was observed among all the samples. The OCP values of all the austenitized samples were higher than that of the annealed one and increased with the increase in austenitizing temperature. This indicated that the passive film formed on the 55Cr18Mo1VN austenitized at higher temperature had a better corrosion resistance during the immersion in $3.5 \mathrm{wt} \% \mathrm{NaCl}$ solution [14].

The potentiodynamic polarization curves of $55 \mathrm{Cr} 18 \mathrm{Mo} 1 \mathrm{VN}$ at different heat-treated temperatures are presented in Fig. 7. The corrosion potential $\left(E_{\text {corr }}\right)$ increased with increasing austenitizing temperature, and 

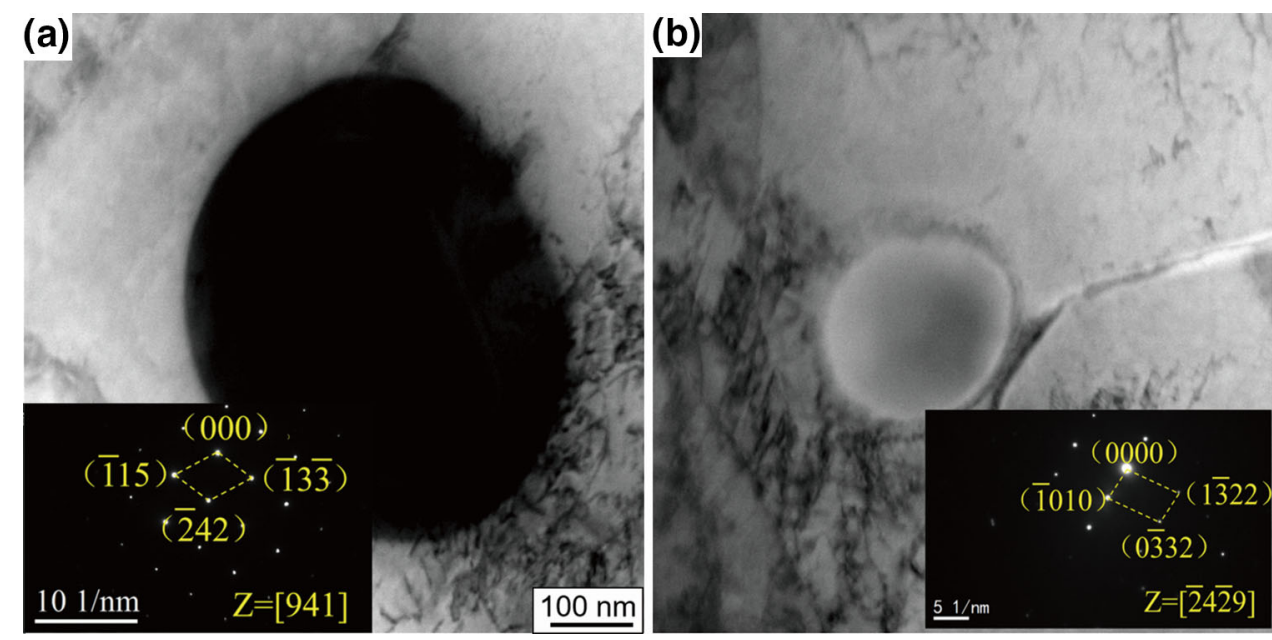

Fig. 5 TEM results of precipitates in the sample austenitized at $940{ }^{\circ} \mathrm{C}: \mathbf{a ~}_{23} \mathrm{Cr}_{6} ; \mathbf{b ~ C r}_{2} \mathrm{~N}$

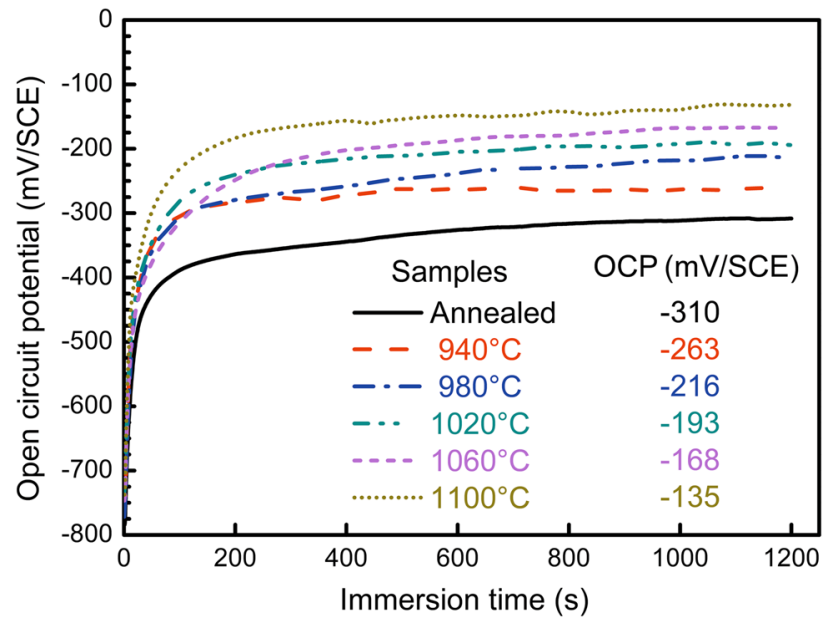

Fig. 6 Evolution of OCP of $55 \mathrm{Cr} 18 \mathrm{Mo} 1 \mathrm{VN}$ steels in $3.5 \mathrm{wt} \% \mathrm{NaCl}$ after cathodic polarization

the tendency was consistent with that of OCP. It can be seen that all the samples showed distinct passivation region and the current density increased significantly above the pitting potential $\left(E_{\mathrm{pit}}\right)$ when stable pitting formed. The corrosion current density $\left(I_{\text {corr }}\right)$ and passive current density $\left(I_{\mathrm{p}}\right)$ decreased rapidly with increasing austenitizing temperature, representing that the anodic dissolution of the steel was slower at higher austenitizing temperature and the protective passive film became more stable. Meanwhile, the $E_{\text {pit }}$ increased with increasing the austenitizing temperature, indicating the enhanced corrosion resistance of the samples austenitized at higher temperature. Similar results were also reported by other researchers [6, 7].

In order to have a good understanding of the passive films formed on the samples austenitized at different temperatures, EIS was carried out under OCP in $3.5 \mathrm{wt} \% \mathrm{NaCl}$ solution. All Nyquist plots (Fig. 8) exhibit semicircle arcs, and the diameter of semicircle arcs increased with the

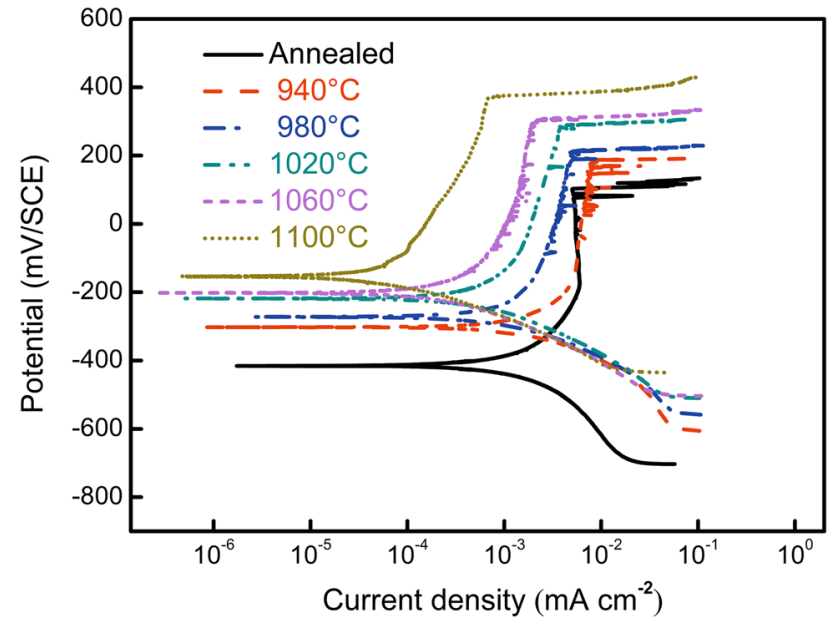

Fig. 7 Potentiodynamic polarization curves of 55Cr18Mo1VN steels in $3.5 \mathrm{wt} \% \mathrm{NaCl}$

increase in austenitizing temperature, relating to the thickening of protective passive film and homogenization of the composition $[7,15]$. The results showed the passive film formed at higher austenitizing temperature had better protective properties in $3.5 \mathrm{wt} \% \mathrm{NaCl}$ solution [16].

The Nyquist plots in Fig. 8 were all well fitted with the model $R_{\mathrm{s}}-Q-R_{\mathrm{p}}$, which was proposed to simulate the behaviour of $\mathrm{Cr} 13$ martensitic stainless steel in $\mathrm{NaCl}$ solution $[7,17]$. The equivalent electric circuit is displayed in Fig. 8, where $R_{\mathrm{s}}$ represents the solution resistance, $R_{\mathrm{p}}$ indicates the charge transfer resistance, and $Q$ (CPE) denotes capacitive behaviour of the passive film. The electric circuit element $Q$ was formulated as Eq. (1):

$Z(\mathrm{CPE})=Q_{0}^{-1}(j \omega)^{-n}$.

The parameter $n$ is the dispersion coefficient relating to surface inhomogeneity [18]. Fitting results in Table 2 show that $n$ and $R_{\mathrm{p}}$ values of the austenitized samples were 


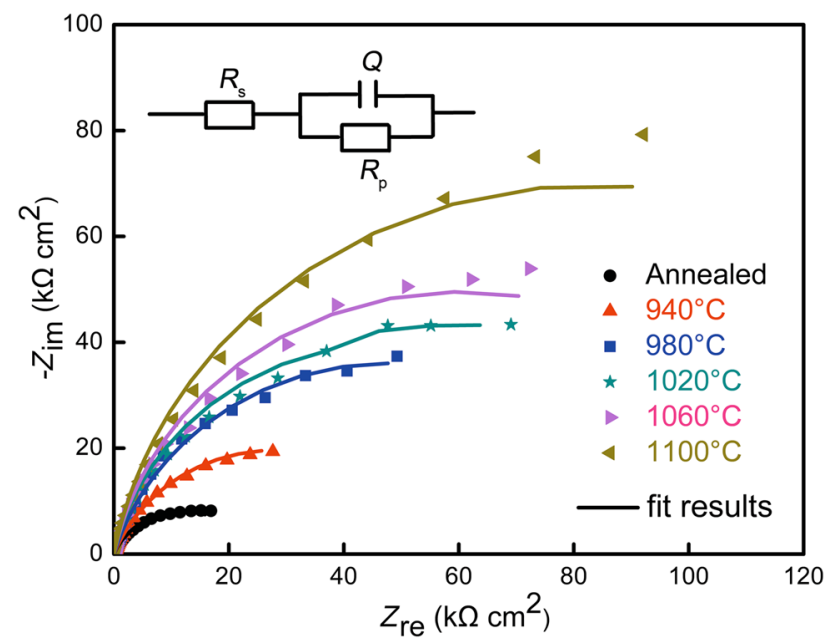

Fig. 8 Nyquist plots of heat-treated $55 \mathrm{Cr} 18 \mathrm{Mo} 1 \mathrm{VN}$ steels in $3.5 \mathrm{wt} \% \mathrm{NaCl}$

higher than those of the annealed one and increased with the increase in austenitizing temperature. It is reported that the thickness of passive film is inversely proportional to capacitance $[19,20]$. The decrease in $Q_{0}$ indicates that higher austenitizing temperature resulted in the thickening of the passive films. Therefore, the samples austenitized at higher temperatures could form better protective passive film in the $\mathrm{Cl}^{-}$containing environment, which is well consistent with the results of potentiodynamic polarization.

\section{Discussion}

\subsection{Effect of Austenitizing Temperature on the Passive Film}

XPS can provide more detailed information about the passive films on the samples austenitized at different temperatures, such as the chemical composition and the depth profile. Therefore, the samples were cathodically polarized at $-1 \mathrm{~V} / \mathrm{SCE}$ for $300 \mathrm{~s}$ to remove original oxide films and then passivated at $0 \mathrm{~V} / \mathrm{SCE}$ for $1 \mathrm{~h}$ to form passive films. The typical XPS spectra of $\mathrm{Cr} 2 p 3 / 2$ and $\mathrm{Fe}$ $2 p 3 / 2$ for the passive film after etching for 10 and $80 \mathrm{~s}$ are displayed in Fig. 9. It is clearly seen that the peaks representing $\mathrm{CrOOH}(576.8 \mathrm{eV}), \mathrm{Cr}_{2} \mathrm{O}_{3}(575.6 \mathrm{eV})$ and metallic $\mathrm{Cr}(573.6 \mathrm{eV})$ are identified in the passive film after etching for $10 \mathrm{~s}$ on the samples austenitized at different temperatures (Fig. 9a). The peak for $\mathrm{CrOOH}$ disappeared in the passive film after etching for $80 \mathrm{~s}$ (Fig. 9b). Similarly, deconvolution of $\mathrm{Fe} 2 p 3 / 2$ spectra reveals the existence of peaks representing $\mathrm{FeOOH}(710.7 \mathrm{eV}), \mathrm{FeO}$ $(709.4 \mathrm{eV}), \mathrm{Fe}_{3} \mathrm{O}_{4}(708.1 \mathrm{eV})$ and metallic $\mathrm{Fe}(706.7 \mathrm{eV})$ in the passive film after etching for $10 \mathrm{~s}$ (Fig. 9c). And the peaks for $\mathrm{FeOOH}$ and $\mathrm{FeO}$ disappeared after etching for $80 \mathrm{~s}$ (Fig. 9d). As mentioned above, the outer layer of the passive film was composed of the oxides $\left(\mathrm{Cr}_{2} \mathrm{O}_{3}, \mathrm{FeO}\right.$ and $\left.\mathrm{Fe}_{3} \mathrm{O}_{4}\right)$ and hydroxides $(\mathrm{CrOOH}$ and $\mathrm{FeOOH})$, and the inner layer mainly contained $\mathrm{Cr}_{2} \mathrm{O}_{3}$ and $\mathrm{Fe}_{3} \mathrm{O}_{4}$. Similar surface analysis results have also concluded that the passive film formed on $\mathrm{Ni}-\mathrm{Cr}-\mathrm{Fe}$ alloy surface is a bilayer film that contains an inner layer rich in $\mathrm{Cr}_{2} \mathrm{O}_{3}$ and an outer layer rich in $\mathrm{Cr}(\mathrm{OH})_{3}$ [21].

As shown in Fig. 9a, the intensity of $\mathrm{CrOOH}$ in the sputtering surface of the passive film for $10 \mathrm{~s}$ increased with increasing austenitizing temperature, which meant that the outer layer of the passive film had less protective effect. In detail, the contents of $\mathrm{Cr}(\mathrm{III})_{\mathrm{CrOOH}}$ and $\mathrm{Cr}(\mathrm{III})_{\mathrm{Cr}_{2} \mathrm{O}_{3}}$ in the samples austenitized at different temperatures were calculated according to Fig. 9a, b. The ratio of $\mathrm{Cr}(\mathrm{III})_{\mathrm{CrOOH}}$ and $\mathrm{Cr}(\mathrm{III})_{\mathrm{Cr}_{2} \mathrm{O}_{3}}$ in the outer layer (sputtering for $10 \mathrm{~s}$ ) of the passive film was 1.6, 0.8 and 0.6 corresponding to the samples austenitized at 940,1020 and $1100{ }^{\circ} \mathrm{C}$, respectively. However, the $\mathrm{CrOOH}$ disappeared in the inner layer of the passive film, and the intensity of $\mathrm{Cr}_{2} \mathrm{O}_{3}$ increased with increasing austenitizing temperature. The percentage of $\mathrm{Cr}(\mathrm{III}) \mathrm{Cr}_{2} \mathrm{O}_{3}$ in the inner layer (sputtering for $80 \mathrm{~s}$ ) of the passive film were 1.38, 1.41 and $2.65 \mathrm{wt} \%$ corresponding to the samples austenitized at 940, 1020 and $1100{ }^{\circ} \mathrm{C}$, respectively. In summary, the amount of

Table 2 Fitting parameters of 55Cr18Mo1VN steels obtained from EIS spectra

\begin{tabular}{lllll}
\hline Specimens $\left({ }^{\circ} \mathrm{C}\right)$ & $R_{\mathrm{S}}\left(\Omega \mathrm{cm}^{2}\right)$ & $\mathrm{CPE}$ & & $R_{\mathrm{p}}\left(\Omega \mathrm{cm}^{2}\right)$ \\
\cline { 2 - 4 } & & $n(0-1)$ & $Q_{0} /\left(\Omega^{-1} \mathrm{~cm}^{-2} \mathrm{~s}^{n}\right)$ & $2.382 \times 10^{4}$ \\
\hline Annealed & 2.986 & 0.7536 & $2.126 \times 10^{-4}$ & $5.613 \times 10^{4}$ \\
940 & 4.399 & 0.7764 & $1.710 \times 10^{-4}$ & $7.248 \times 10^{4}$ \\
980 & 1.382 & 0.8726 & $1.000 \times 10^{-4}$ & $9.721 \times 10^{4}$ \\
1020 & 3.702 & 0.8730 & $7.832 \times 10^{-5}$ & $1.209 \times 10^{5}$ \\
1060 & 3.021 & 0.8744 & $7.620 \times 10^{-5}$ & $1.670 \times 10^{5}$ \\
1100 & 2.158 & 0.8865 & $6.330 \times 10^{-5}$ & \\
\hline
\end{tabular}



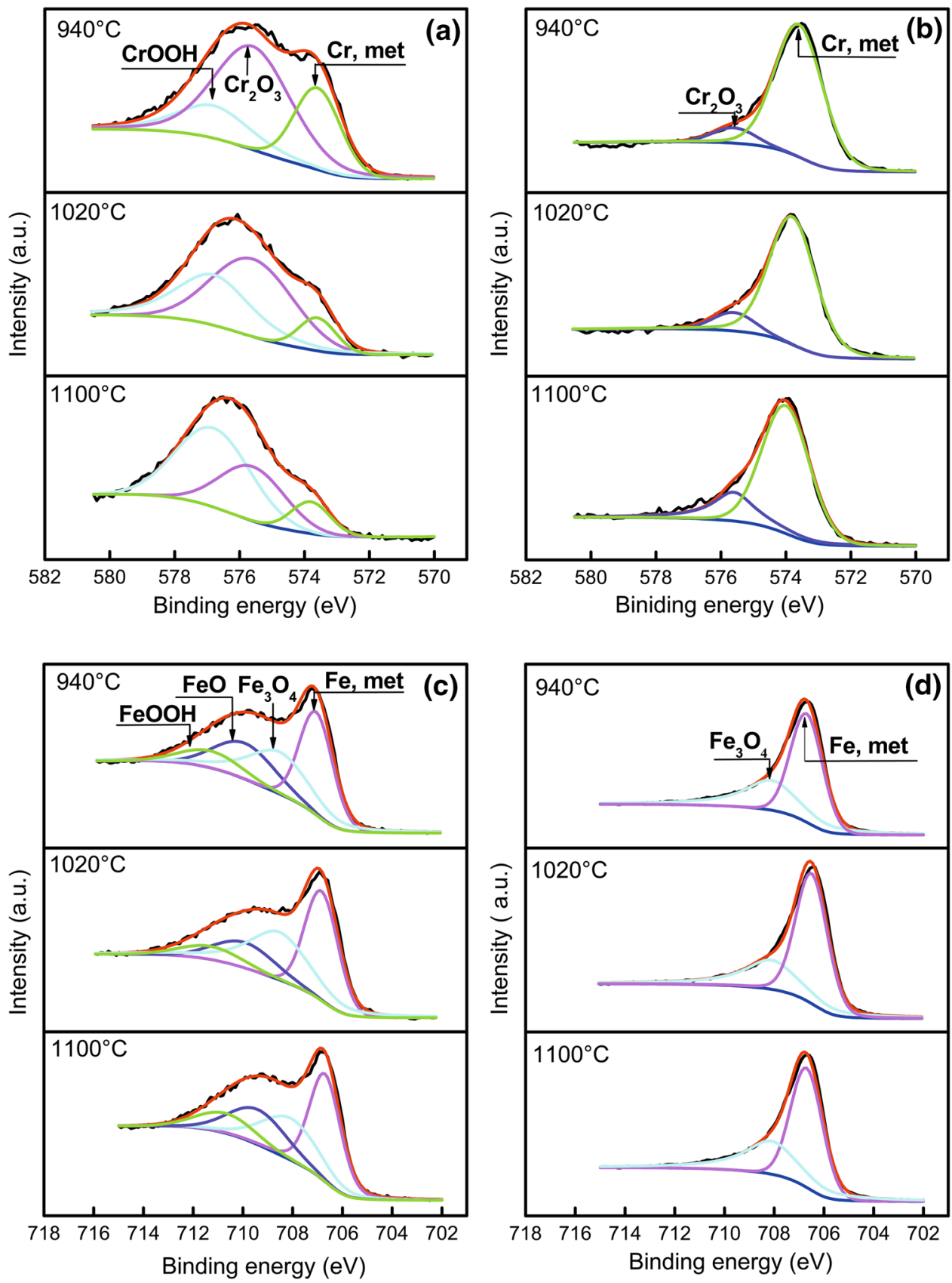

Fig. 9 Detailed XPS spectra of a, b Cr 2p3/2, c, d Fe 2p3/2 recorded from sputtering surface of passive film for 10 and $80 \mathrm{~s}$

$\mathrm{Cr}(\mathrm{III})_{\mathrm{CrOOH}}$ in the outer layer increased with increasing austenitizing temperature, but the content of $\mathrm{Cr}(\mathrm{III})_{\mathrm{Cr}_{2} \mathrm{O}_{3}}$ in the inner layer increased obviously, which means that the increment of $\mathrm{Cr}(\mathrm{III})_{\mathrm{Cr}_{2} \mathrm{O}_{3}}$ in the inner layer would play an important role in the improved corrosion resistance with increasing austenitizing temperature. The intensity of $\mathrm{Cr}$ metal decreased with the increasing of austenitizing temperature, which indicated that the passive film became thicker at higher austenitizing temperature [22]. In addition, the $\mathrm{Cr}(\mathrm{III}) /(\mathrm{Fe}(\mathrm{II})+\mathrm{Fe}(\mathrm{III}))$ ratio in the inner layer increased with austenitizing temperature (Fig. 10), indicating the enrichment of $\mathrm{Cr}(\mathrm{III})$ and thickening of passive film at higher austenitizing temperature. These contributed to higher stability in $3.5 \mathrm{wt} \% \mathrm{NaCl}$ solution, which was revealed by the increased values of OCP, $E_{\text {corr }}$ and $R_{\mathrm{p}}$ (Figs. 6, 7; Table 2).

The N $1 s$ spectra for the outermost of the passive films were decomposed into $\mathrm{NH}_{3}(399.8 \mathrm{eV})$ and $\mathrm{CrN}$ $(396.6 \mathrm{eV})$, as shown in Fig. 11a. After etching for $10 \mathrm{~s}$, the passive films contained only one peak representing 


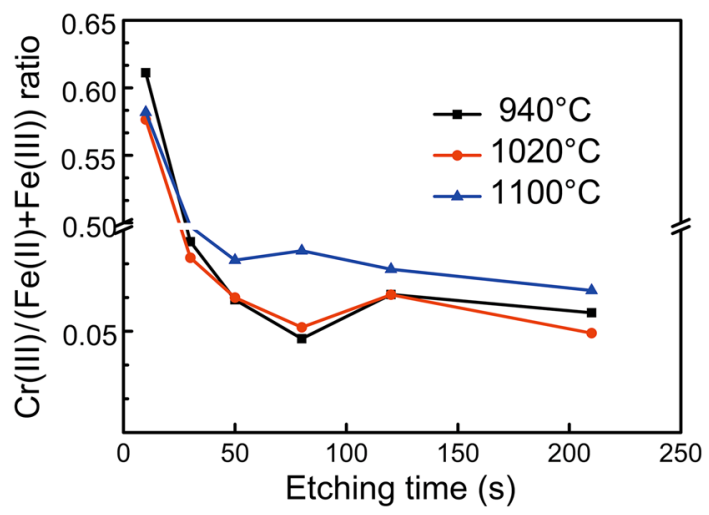

Fig. 10 Variation of $\mathrm{Cr}(\mathrm{III})$ to $(\mathrm{Fe}(\mathrm{II})+\mathrm{Fe}(\mathrm{III}))$ ratio in passive film with etching time for the samples austenitized at different temperatures

$\mathrm{CrN}$. In the pitting corrosion process, $\mathrm{CrN}$ was generated in the passive film because of anodic segregation [23]. During the propagation of the pits, $\mathrm{CrN}$ may act as a precursor to passive film formation and form $\mathrm{NH}_{3}$ in dissolution process through Eq. (2):

$2 \mathrm{CrN}+3 \mathrm{H}_{2} \mathrm{O} \rightarrow \mathrm{Cr}_{2} \mathrm{O}_{3}+2 \mathrm{NH}_{3}$ (ligands).

Besides, $\mathrm{NH}_{3}$ can also be formed by the dissolution of atomic nitrogen in matrix as Eq. (3):

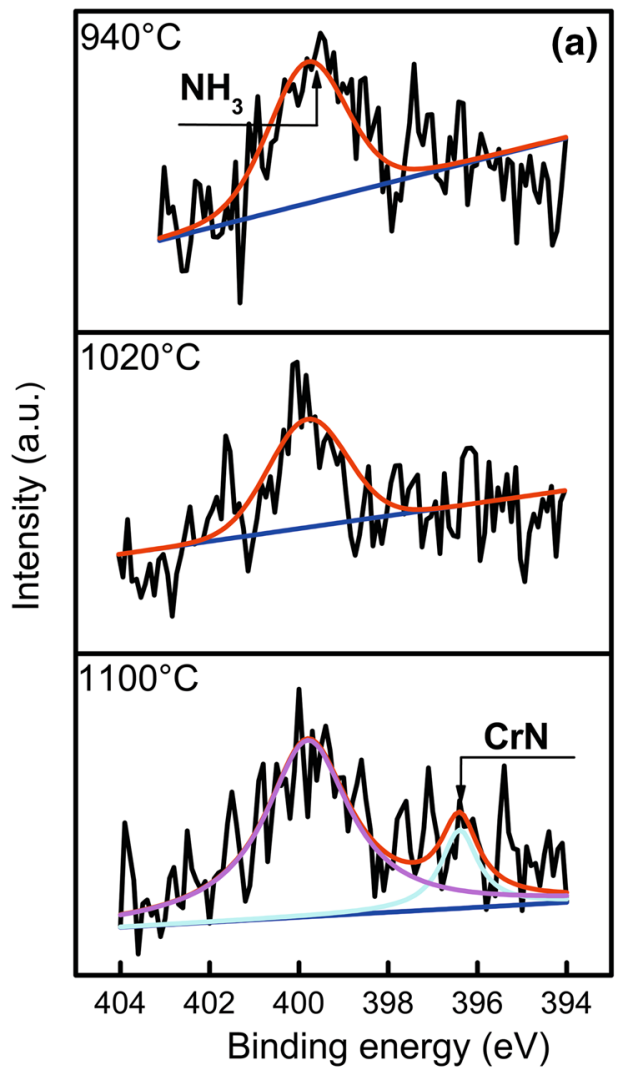

$[\mathrm{N}]+3 \mathrm{H}^{+}+3 \mathrm{e}^{-} \rightarrow \mathrm{NH}_{3} \quad$ (ligands)

As a result, $\mathrm{H}^{+}$produced by self-catalytic mechanism [24] could be partially consumed, and the local acidification in the pits can be effectively inhibited, hence promoting the repassivation of pits. Many studies by XPS demonstrated that the alloyed $\mathrm{N}$ in the matrix was released into the solution in a form of $\mathrm{NH}_{3}\left(\mathrm{NH}_{4}{ }^{+}\right)$during the matrix dissolution [22, 25]. With increasing austenitizing temperature, the content of nitrogen in solid solution increased (Fig. 4), which improved the content of $\mathrm{CrN}$ and $\mathrm{NH}_{3}$. Therefore, the repassivation ability of 55Cr18Mo1 VN steel was increased with austenitizing temperature.

\subsection{Effect of Austenitizing Temperature on Pitting Corrosion Mechanism}

The pit initiation sites in the sample austenitized at $940{ }^{\circ} \mathrm{C}$ were investigated by FE-SEM as shown in Fig. 12a. It can be seen that several metastable pits around precipitates could be observed. Metastable pits were considered as the initiation stage of pitting corrosion, and they might develop to stable pits $[26,27]$. In order to clearly recognize the location of the metastable pits, the magnified morphology of the metastable pit zone is exhibited in Fig. 12b. The

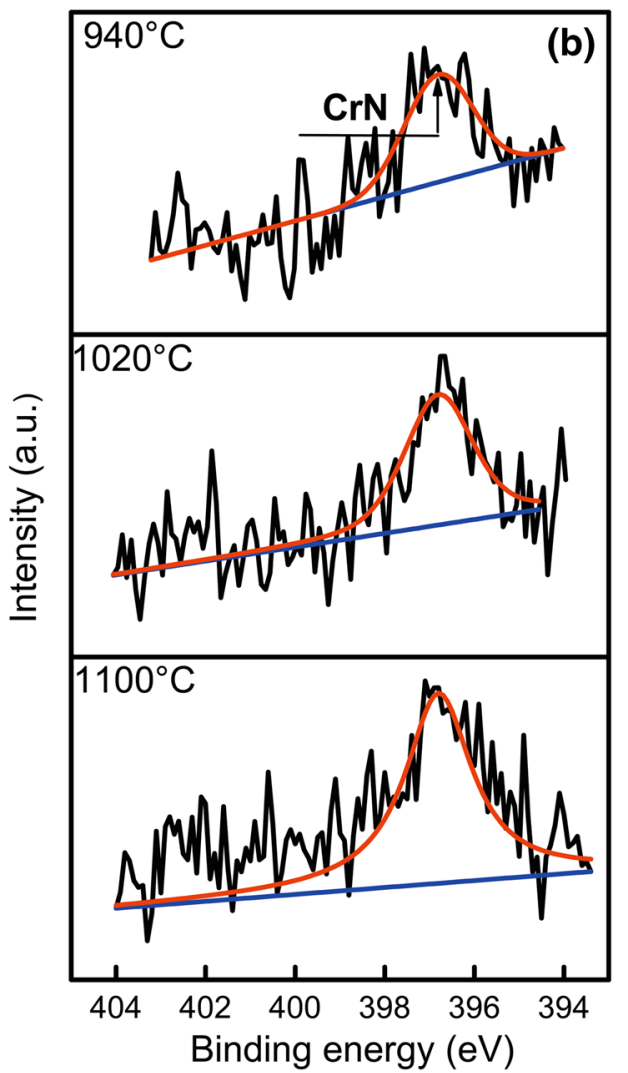

Fig. 11 Detailed XPS spectra of N $1 \mathrm{~s}$ recorded from the outmost a and sputtering surface $\mathbf{b}$ of the passive film for $10 \mathrm{~s}$ on samples austenitized at different temperatures 


\section{(a)}

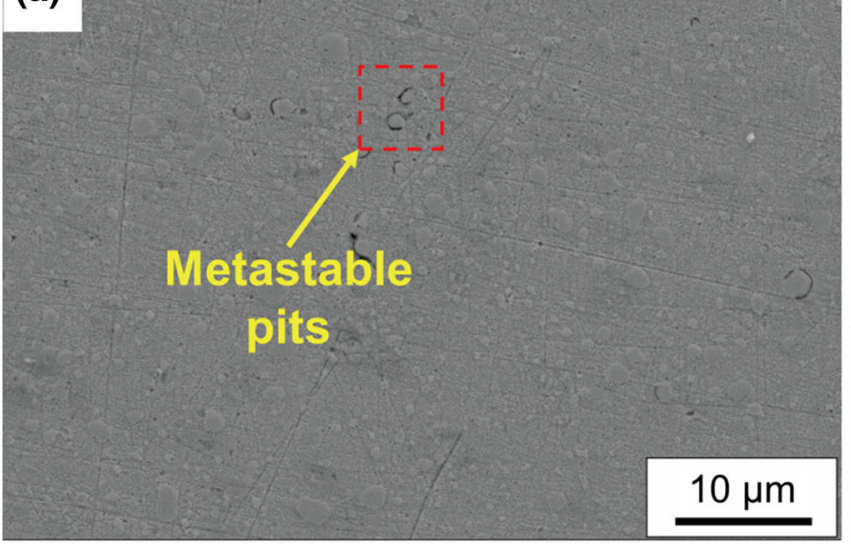

\section{(b)}

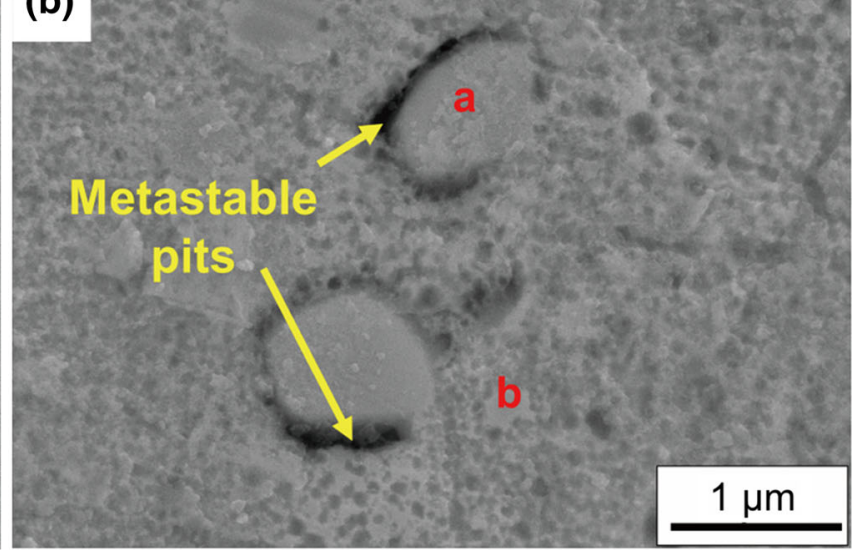

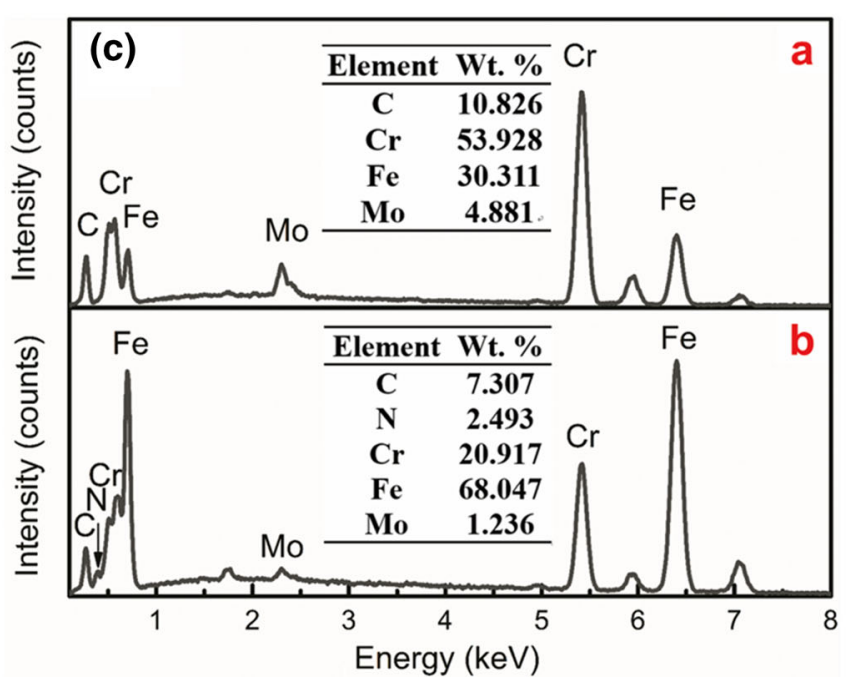

Fig. 12 SEM images of the pit initiation sites on the sample austenitized at $940{ }^{\circ} \mathrm{C}$ : a metastable pits; b the local magnification of the metastable pits; $\mathbf{c}$ EDS analysis of precipitates exhibited in $\mathbf{b}$

metastable pits were only observed around the precipitates with larger size. The composition analysis via EDS (Fig. 12c) indicated that precipitate with larger size (point a) was carbide, and precipitate with smaller size (point b) was nitride. This indicated that the pitting corrosion occurred preferentially around coarse carbides. Besides, the volume fraction of precipitates decreased with increasing austenitizing temperature (Fig. 3), which means the decrease in the pit initiation sites, thus the increase in the corrosion resistance.

TEM images of the precipitates in the sample austenitized at $940{ }^{\circ} \mathrm{C}$ are shown in Fig. 13a, c. The $\mathrm{Cr}$ content profiles from $M_{23} \mathrm{C}_{6} / M_{2} \mathrm{~N}$ to the matrix along the lines marked in Fig. 13a, c are shown in Fig. 13b, d, and the $\mathrm{Cr}$ depletion was observed at the interface of precipitates and the matrix. Similar Cr-depleted zones around Cr-rich precipitates, such as $\mathrm{Cr}_{2} \mathrm{~N}, \mathrm{Cr}_{23} \mathrm{C}_{6}, \sigma$ and $\chi$, were reported previously $[28,29]$. Due to the lower chromium concentration, the Cr-depleted zone has less stable passive film [30], and acts as narrow anodic zone [13] during corrosion process, inducing higher corrosion sensitivity. Therefore, the Cr-depleted zone was regarded as one of the factors responsible for the corrosion of the stainless steel [27]. In addition, the width and minimum $\mathrm{Cr}$ concentration of the Cr-depleted zone (Fig. 13) caused by $\mathrm{Cr}_{23} \mathrm{C}_{6}$ was severer than those by $\mathrm{Cr}_{2} \mathrm{~N}$, which resulted from the smaller size of $\mathrm{Cr}_{2} \mathrm{~N}$ than $\mathrm{Cr}_{23} \mathrm{C}_{6}$. The Cr-depleted zone results are in reasonable agreement with the preferential initiation sites around the carbides (Fig. 12).

As is well known, the Cr-rich carbides and nitrides acting as preferential sites for pitting corrosion decrease the corrosion resistance of the steel [31]. With increasing austenitizing temperature, more precipitates dissolved in the matrix. Less $\mathrm{Cr}$-depleted zones and more homogeneous distribution of chromium (Fig. 4c) in the matrix at higher austenitizing temperature were beneficial to improving values of OCP, $E_{\text {corr }}, E_{\mathrm{pit}}$ and $R_{\mathrm{p}}$ (Figs. 6, 7; Table 2) and decreasing values of $I_{\mathrm{r}}$ and $I_{\mathrm{p}}$ (Fig. 7). Therefore, the corrosion resistance of $55 \mathrm{Cr} 18 \mathrm{Mo} 1 \mathrm{VN}$ was enhanced with the increase in austenitizing temperature. 

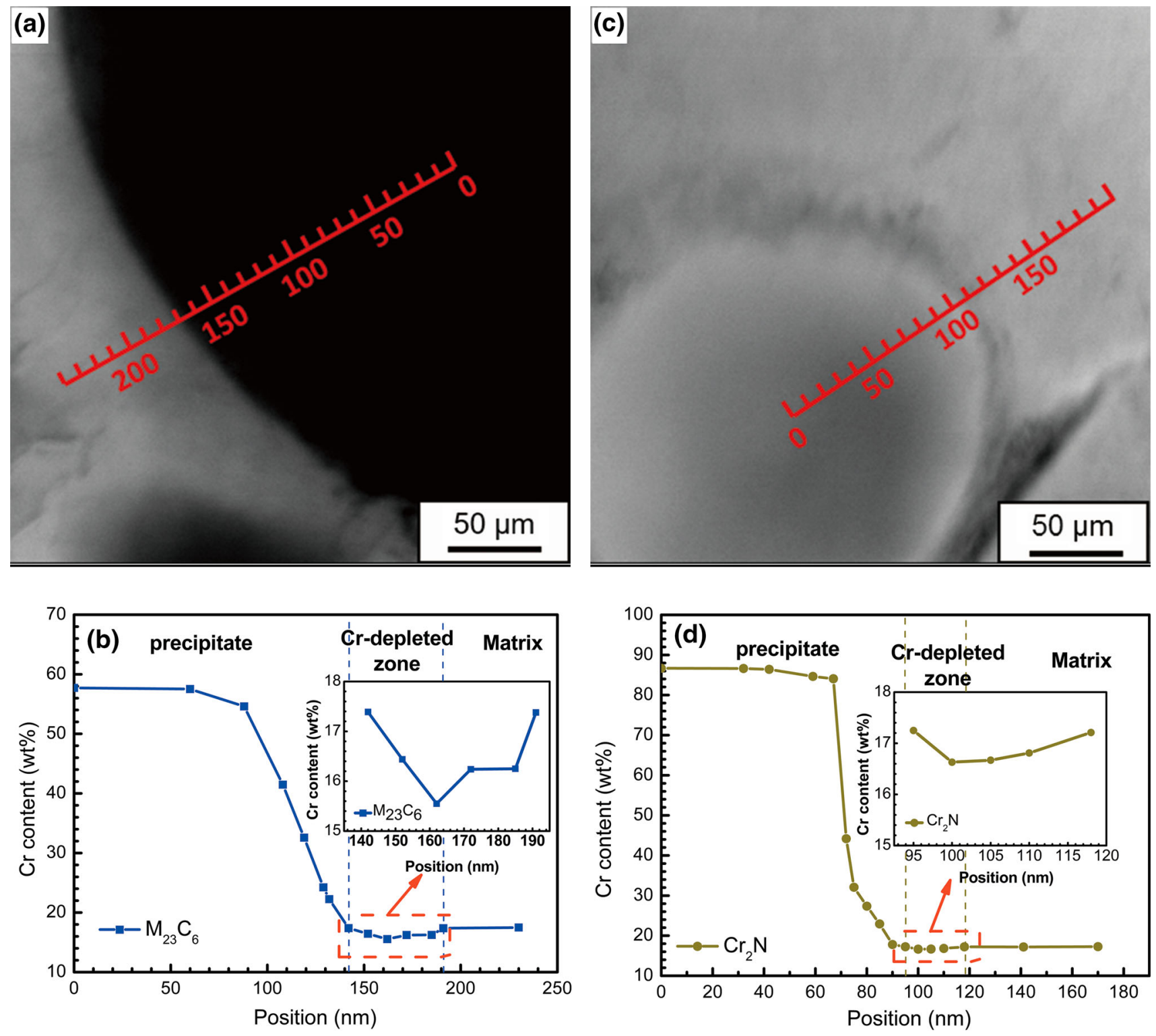

Fig. 13 a, c TEM images of precipitates in the sample austenitized at $940{ }^{\circ} \mathrm{C}: \mathbf{a ~}_{23} \mathrm{Cr}_{6} ; \mathbf{c} \mathrm{Cr}_{2} \mathrm{~N}$; b corresponding Cr-depleted zone of a; d corresponding $\mathrm{Cr}$-depleted zone of $\mathbf{c}$

Based on the results of microstructure and corrosion resistance, the schematic illustration of pitting corrosion mechanism of $55 \mathrm{Cr} 18 \mathrm{Mo} 1 \mathrm{VN}$ austenitized at low and high temperature is shown in Fig. 14. A large amount of undissolved precipitates existed in the sample austenitized at low temperature (Fig. 14a), and most of the precipitates were dissolved into the matrix at high austenitizing temperature (Fig. 14b), resulting in higher content of $\mathrm{C}, \mathrm{N}$ and $\mathrm{Cr}$ in the matrix. $\mathrm{Cr}$-rich precipitates induced the existence of $\mathrm{Cr}$-depleted zone, and the degree of $\mathrm{Cr}$ depleted zone around $M_{23} \mathrm{C}_{6}$ was severer than that around $M_{2} \mathrm{~N}$. And metastable pitting corrosion initiated preferentially around the coarse $M_{23} \mathrm{C}_{6}$ carbides. The less stable passive film around the precipitates corroded with $\mathrm{Cl}^{-}$ions, forming $M \mathrm{Cl}_{n}$ compound. Then, the $M \mathrm{Cl}_{n}$ reacted with $\mathrm{H}_{2} \mathrm{O}$ in the solution to generate $M(\mathrm{OH})_{n}, \mathrm{Cl}^{-}$and $\mathrm{H}^{+}$ions, inducing low $\mathrm{pH}$ value and accelerating the local dissolution rate by self-catalytic mechanism. The high content of nitrogen in solid solution at high austenitizing temperature was beneficial to the formation of $\mathrm{CrN}$ and $\mathrm{NH}_{3}$ (Fig. 14b), leading to the increase in $\mathrm{pH}$ value in the pit and promoting the repassivation of the $55 \mathrm{Cr} 18 \mathrm{Mo} 1 \mathrm{VN}$ steel.

\section{Conclusions}

1. With increasing austenitizing temperature, the volume fraction of Cr-rich precipitates decreased and retained 


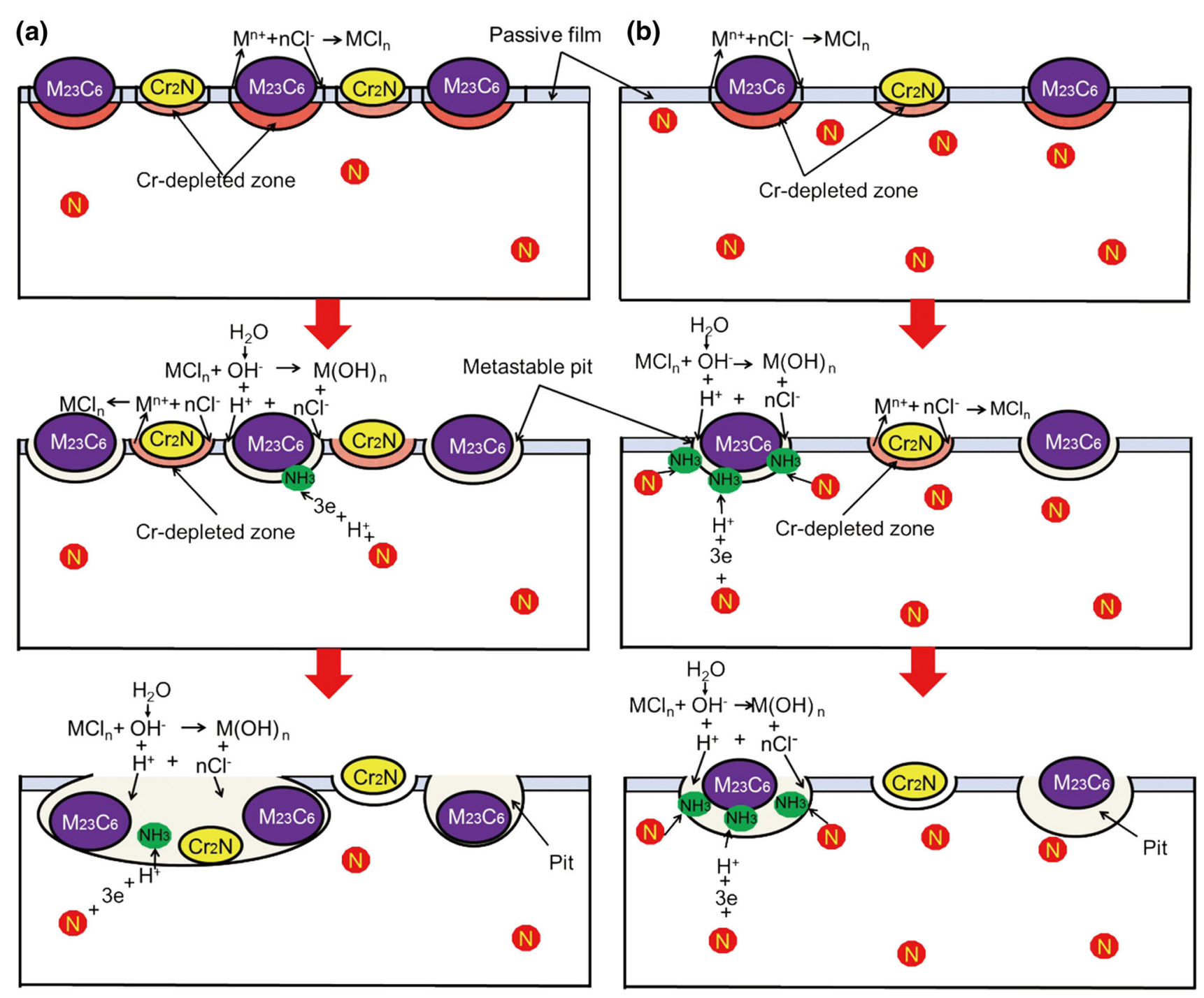

Fig. 14 Schematic illustration of pitting corrosion mechanism for $55 \mathrm{Cr} 18 \mathrm{Mo} 1 \mathrm{VN}$ steel austenitized at a low, b high temperatures

austenite increased, inducing more uniformly elemental distribution and enhancing content of $\mathrm{C}, \mathrm{N}$ and $\mathrm{Cr}$ in the matrix. The precipitates were identified as $\mathrm{Cr}_{23} \mathrm{C}_{6}$ and $\mathrm{Cr}_{2} \mathrm{~N}$, and the degree of $\mathrm{Cr}$-depleted zone around $\mathrm{Cr}_{23} \mathrm{C}_{6}$ was severer than that around $\mathrm{Cr}_{2} \mathrm{~N}$.

2. The increase in austenitizing temperature enhanced the values of OCP, $E_{\text {corr }}, E_{\text {pit }}$ and $R_{\mathrm{p}}$ and decreased the values of $I_{\mathrm{r}}$ and $I_{\mathrm{p}}$. Corrosion resistance of $55 \mathrm{Cr} 18 \mathrm{Mo} 1 \mathrm{VN}$ was improved with increasing austenitizing temperature. Pitting corrosion initiated preferentially around the coarse $M_{23} \mathrm{C}_{6}$ carbides.

3. With the increase in austenitizing temperature, the passive film was thickened and $\mathrm{Cr}(\mathrm{III})_{\mathrm{Cr}_{2} \mathrm{O}_{3}}$ in the inner layer of passive film was enriched, which enhanced the corrosion resistance of steel. The higher content of nitrogen in solid solution at higher austenitizing temperature contributed to the increased intensities of
$\mathrm{CrN}$ and $\mathrm{NH}_{3}$, leading to the increase in $\mathrm{pH}$ value in the pit and promoting the repassivation of 55Cr18Mo1VN steel.

Acknowledgments The present research was financially supported by National Natural Science Foundation of China (Grant Nos.51304041, 51434004 and U1435205) and Fundamental Research Funds for the Central Universities (Grant No. N150204007).

\section{References}

[1] K. Sammt, J. Sammer, J. Geckle, W. Liebfahrt, in Proceedings to the 6th International Tooling Conference (Karlstad, Sweden, 2002) 10-13 September

[2] O. Ozturk, O. Onmus, D.L. Williamson, Surf. Coat. Technol. 196, 333 (2005)

[3] R. Schneider, J. Perko, G. Reithofer, Mater. Manuf. Processes 24, 903 (2009) 
[4] S. Zinner, H. Lenger, I. Siller, BHM 155, 313 (2010)

[5] A. Beneteau, P. Weisbecker, G. Geandier, E. Aeby-Gautier, B. Appolaire, Mater. Sci. Eng. A 393, 63 (2005)

[6] Y.S. Choi, J.G. Kim, Y.S. Park, J.Y. Park, Mater. Lett. 61, 244 (2007)

[7] S.Y. Lu, K.F. Yao, Y.B. Chen, M.H. Wang, Y. Shao, X.Y. Ge, J. Appl. Electrochem. 45, 375 (2015)

[8] K. Kaneko, T. Fukunaga, K. Yamada, N. Nakada, M. Kikuchi, Z. Saghi, J.S. Barnard, P.A. Midgley, Scr. Mater. 65, 509 (2011)

[9] A. Rajasekhar, G. Madhusudhan Reddy, T. Mohandas, V.S.R. Murti, Mater. Des. 30, 1612 (2009)

[10] W. Trojahn, E. Streit, H.A. Chin, D. Ehlert, Mater. Sci. Eng. Technol. 30, 605 (1999)

[11] A. Toro, W.Z. Misiolek, A.P. Tschiptschin, Acta Mater. 51, $3363(2003)$

[12] J. Sun, Y.T. Zhang, P. Wang, Z.F. Ye, D.Z. Li, Acta Metall. Sin. (Engl. Lett.) 27, 573 (2014)

[13] H. Berns, R. Ehrhardt, Steel Res. 67, 343 (1996)

[14] H.B. Li, Z.H. Jiang, H. Feng, S.C. Zhang, P.D. Han, W. Zhang, G.P. Li, G.W. Fan, Int. J. Electrochem. Sci. 10, 4832 (2015)

[15] J.L. Lv, H.Y. Luo, Appl. Surf. Sci. 263, 29 (2012)

[16] M. Sun, M. Luo, C. Lu, T.W. Liu, Y.P. Wu, L.Z. Jiang, J. Li, Acta Metall. Sin. (Engl. Lett.) 8, 1089 (2015)

[17] S.S.E. Egamy, W.A. Badaway, J. Appl. Electrochem. 24, 1153 (2004)
[18] S.Y. Lu, K.F. Yao, Y.B. Chen, M.H. Wang, X.Y. Ge, Metall. Mater. Trans. A 46, 6090 (2015)

[19] G.Z. Meng, Y. Li, Y.W. Shao, T. Zhang, Y.Q. Wang, F.H. Wang, J. Mater. Sci. Technol. 30, 253 (2014)

[20] N. Piao, J. Chen, C.J. Yin, C. Sun, X.H. Zhang, Z.W. Wu, Acta Metall. Sin. 51, 1077 (2015). (in Chinese)

[21] M.V. Cardoso, S.T. Amaral, E.M.A. Martini, Corros. Sci. 50, 2429 (2008)

[22] Y. Fu, X.Q. Wu, E.H. Han, W. Ke, K. Yang, Z.H. Jiang, Electrochim. Acta 54, 4005 (2009)

[23] R.D. Willenbruch, C.R. Clayton, M. Oversluizen, D. Kim, Y. Lu, Corros. Sci. 31, 179 (1990)

[24] N. Du, W.M. Tian, Q. Zhao, S.B. Chen, Acta Metall. Sin. 48, 807 (2012). (in Chinese)

[25] R.F.A.J. Pettersson, Corros. Sci. 41, 1639 (1999)

[26] G.S. Frankel, J. Electrochem. Soc. 145, 33 (1998)

[27] Y.J. Guo, T.Y. Sun, J.C. Hu, Y.M. Jiang, L.Z. Jiang, J. Li, J. Alloys Compd. 658, 1031 (2016)

[28] A. Moteshakker, I. Danaee, J. Mater. Sci. Technol. 32, 282 (2016)

[29] G.S. Bai, S.P. Lu, D.Z. Li, Y.Y. Li, Corros. Sci. 90, 347 (2015)

[30] G.S. Bai, S.P. Lu, D.Z. Li, Y.Y. Li, J. Electrochem. Soc. 162, C473 (2015)

[31] A. Rajasekhar, Int. J. Sci. Res. 4, 2795 (2015) 